\title{
EFFECT OF OCCLUSAL VERTICAL DIMENSION OF COMPLETE DENTURE ON MAXIMUM BITING FORCE
}

\author{
Emad B. Abdel-Salam*, Yasmeen F. Almahdy ${ }^{* *}$, Yaser A. Baraka*** and Hesham I. Mostafa ${ }^{* * * *}$
}

\begin{abstract}
Ten completely edentulous male patients; ranging in age from 45 to 50 years, were selected to study the effect of changing the vertical dimension of occlusion of complete denture wearers on the maximum biting force. For each patient five heat cured acrylic resin record blocks were constructed with different vertical dimensions. Bilateral seats in the premolar area were prepared within the occlusion rim to accommodate for the load cell used in biting measurement. The height of the load cell was $8 \mathrm{~mm}$ while the seats were prepared to be one $\mathrm{mm}$ less than the height of the load cell to facilitate the registration of the biting force. The base of the seat was prepared parallel to the occlusal plane. The biting force measurements were done by the record blocks with different vertical dimensions unilaterally (right side then left side measurements). The results of this study showed the values of biting forces upon changing the vertical dimension of occlusion in the right and left sides. When the vertical dimension of occlusion increased $3 \mathrm{~mm}$ there was an increase in the maximum biting force, while when the vertical dimension of occlusion increased $6 \mathrm{~mm}$; the maximum biting force was decreased than that values obtained by $3 \mathrm{~mm}$ increase in vertical dimension. On the other hand when the vertical dimension of occlusion was decreased by $3 \mathrm{~mm}$ and $6 \mathrm{~mm}$, the maximum biting force was decreased. The results of the present study concluded that the vertical dimension of occlusion is not an optimal vertical dimension that produces the maximum biting forces.
\end{abstract}

\section{INTRODUCTION}

The determination of the correct vertical dimension of occlusion for edentulous patients is one of the most important steps for constructing the dentures with adequate esthetics and functions ${ }^{(1)}$. The position of the condyles does affect muscle length and hence the vertical dimension of occlusion VDO. When looking at changes in vertical dimension VD it is paramount to mount the study casts in centric relation (CR) (when the heads of the condyles are in their most superior position within their sockets, with the discs properly aligned and full neuromuscular release ${ }^{(2)}$. An increase in the vertical dimension of occlusion beyond postural

\footnotetext{
* Associate Professor of Removable Prosthodontics, Faculty of Dental Medicine, Al-Azhar University (Assiut branch). ** Associate Professor of Removable Prosthodontics, Faculty of Dental Medicine, Al-Azhar University (Girls branch). *** Lecturer of Removable Prosthodontics, Faculty of Dentistry, Saina University. **** Lecturer of Removable Prosthodontics, Faculty of Oral and Dental Medicine, Future University.
} 
rest position causes an increase in muscle activity in the jaw-closing muscles as the musculature attempts to recover the individual's original interocclusal clearance $^{(3,4)}$. The effect of change of the vertical dimension on the bite force or electromyographic activities of the masticatory muscles has been studied by many investigators. The results of some of these studies indicate that the maximum biting force is exerted around the rest position ${ }^{(5)}$, while those of the others indicate that it is exerted at greater vertical dimensions of occlusion ${ }^{(6)}$. The electromyographically recorded postural muscle activity was lower with splints than without them. The increase of the occlusal vertical dimension thus seems not to induce increased muscle activity to restore the original vertical dimension of occlusion. The lower postural activity with splints and in the anterior temporalis muscles also lowered the mandibular positions ${ }^{(7)}$. These were in accordance with the results from many studies demonstrating that lowering of the mandible leads to decreased muscle activities ${ }^{(8)}$. Increasing the vertical dimension in both subjects with natural teeth and with complete dentures resulted in deranging the function of muscles and joints of the masticatory system, and therefore may be considered to be a hazardous procedure in prosthetic treatment ${ }^{(9)}$.

Gunnar et al ${ }^{(10)}$ studied the effect of moderate increasing the vertical dimension of occlusion in six adult persons with completely natural dentition by using an acrylic resin splint cemented and covering the lower canine, premolar, and molar teeth. They found that the subjects experienced a moderate symptom of discomfort upon placement of the splint, and these symptoms decreased upon the end of the study period. The authors concluded that the moderate increase of the vertical dimension of occlusion does not seem to be a hazardous procedure.

The level of muscle activity was highest at what could be considered a clinically acceptable occlusal vertical dimension and decreased when the occlusal vertical dimension was increased. The authors concluded from the study that discomfort from complete denture with an increased occlusal vertical dimension might not be related to increased muscle activity, and the adverse response to increased occlusal vertical dimension only occurs in few patients ${ }^{(11,12)}$. The effect of the vertical dimension of occlusion on facial aesthetics was studied on 96 patients. The patients had been treated in the practice during the period of 3 years, resulting in an overall $72 \%$ response ${ }^{(13)}$. All these patients had their occlusal vertical dimension increased. Photographs of patients were taken before, during and after treatment. The questionnaire asked their opinion on the effects of the treatment on their facial features. To obtain an objective view to substantiate the opinions of the patients, a panel of five judges reviewed before and after photographs and filled in their own questionnaires. The authors found that the patients who responded to the questionnaire, $79.7 \%$ said they looked younger after the treatment. The panel thought $81.2 \%$ of the patients treated looked younger. The authors concluded that increasing the vertical dimension of occlusion can have far reaching effects on facial aesthetics, not just on the peri-oral areas but on the whole face.

The excessive interocclusal distance results in a reduced interarch distance when the teeth are in occlusion. This over closure in occlusion is potentially damaging to the tempromandibular joints, the normal tongue space is limited, facial distortion appears more noticeable with overclosure than with slightly opened closure as the chin appears to be closer to the nose, the commissure of the lips turns down and the lips lose their fullness, the muscles of facial expression lose their tonicity and the face appears flabby instead of being firm ${ }^{(14)}$. The hypotheses that postural rest position is fixed and unchanging throughout life and that restorations or prostheses that encroach on the postural rest position may cause pathologic squeal appear to be unsound, and seems reasonable to accept an alternate 
hypothesis that the correct or physiologic occlusal vertical dimension can better be described as a range instead of a fixed point or position for most subjects. The authors added that the width of that comfort zone may vary among individuals and in a single individual at different times, since individual adaptive capacity is unknown. They also described the occlusal vertical dimension, to be like other quantifiable aspects of a body or system function, such as blood pressure per weight, for example, is unlikely to be a rigid, specific, and unchangeable entity; hence, the conventional clinical wisdom of regarding it as a variable range ${ }^{(15)}$.

Denture wearers whose maxillary support tissues were good for denture retention and stability were able to biting with more than twice the force of denture wearers with unsatisfactory denture support tissues before denture dislodgment occurred ${ }^{(16)}$. The occlusal forces during swallowing are produced by light bilateral occlusal contact at the normal vertical dimension. In contrast, chewing and maximum biting are most often unilateral at a slightly increased vertical dimension ${ }^{(17)}$. The author also noted that unilateral occlusal force measurement could result in asymmetric loading of the tempromandibular joints and inhibition of muscle activity. Since most occlusal force measurement has been accomplished unilaterally without support for the contra-lateral side of the occlusion, occlusal forces need to be measured with and without contra lateral support to evaluate the validity of unilateral force measurement techniques. The decline of occlusal support and general health might translate into reduction of bite force with aging in older adults. Since tooth loss is not physiological ageing but pathological ageing, we cannot show that reduction of bite force is a natural effect of ageing. Maintaining a reasonable number of healthy natural teeth and occlusal support is the best guarantee for good masticatory ability with increasing age ${ }^{(18)}$. The purpose of this research work was to study the effect of changing the occlusion vertical dimension of complete denture on the maximum biting force.

\section{MATERIALS AND METHODS}

Ten completely edentulous male patients; ranging in age from 45 to 50 years, were selected. For each patient five record blocks were constructed. The first record block was adjusted accurately to a vertical dimension of occlusion and used as a control. While the second record block was adjusted to a vertical dimension lower than the vertical dimension of occlusion by $3 \mathrm{~mm}$; the third record block was adjusted to a vertical dimension lower than the vertical dimension of occlusion by $6 \mathrm{~mm}$. On the other hand, the fourth record block was adjusted to a vertical dimension higher than the vertical dimension of occlusion by $3 \mathrm{~mm}$, and then the last record block was adjusted to a vertical dimension higher than the vertical dimension of occlusion by $6 \mathrm{~mm}$. For each record block the centric relation was recorded and checked in the patient's mouth. Bilateral seats in the premolar areas were prepared within the wax occlusion rim to accommodate for the load cell used in biting measurement (fig 1).

\section{Preparation for Biting Force Measurement}

In the five record blocks with different vertical dimensions, the height of the load cell was $8 \mathrm{~mm}$ while the seats were prepared to be one mm less than the height of the load cell to facilitate the registration of the biting force. The base of the seat was prepared parallel to the occlusal plane.

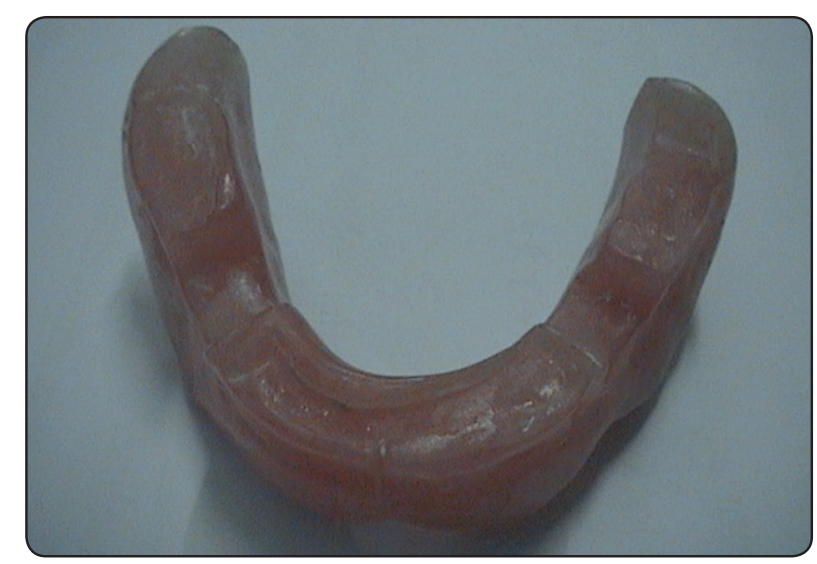

Fig. (1): A bilateral seat in the premolar area in record block. 
Then the prepared record blocks were flasked, and the wax occlusion rim converted to acrylic resin.

\section{Biting Force Measurement}

After completion of the preparation of the record blocks, biting force measurements were done, the patient was seated upright in a dental chair. The bite force display screen was hidden from the patient. The patient was requested to bite unilaterally (right side then left side measurement), and the maximum biting force was recorded. The patient's rested until they felt comfortable (usually 3 to 5 minutes) after each record. The load cell was connected to an amplifier and data logger that introduce the readings to the computer that display the readings in $\mathrm{kg}$. All measurements were recorded and tabulated. Statistical analysis of the results including the mean, standard deviation, mean differences, and paired " $t$ " test were calculated (between the different measurements).

\section{RESULTS}

The results of this study showed that when the vertical dimension of occlusion increased $3 \mathrm{~mm}$ there was an increase in the maximum biting force, while when the vertical dimension of occlusion increased $6 \mathrm{~mm}$; the maximum biting force was decreased than that values obtained by $3 \mathrm{~mm}$ increase in vertical dimension. On the other hand when the vertical dimension of occlusion was decreased by $3 \mathrm{~mm}$ and $6 \mathrm{~mm}$, the maximum biting force was decreased.

Table (1 \& 2) shows the mean differences, standard deviations, paired t- and P-values of biting forces upon changing the vertical dimension of occlusion in the right and left sides. On comparing the values of biting force at the vertical dimension of occlusion versus the values of biting force at the vertical dimension of occlusion $+3 \mathrm{~mm},+6 \mathrm{~mm},-3$ $\mathrm{mm}$ and $-3 \mathrm{~mm}$.; the difference between both vertical dimensions were highly significant $(\mathrm{P}<0.01)$.
TABLE (1) The mean differences, standard deviations, paired $\mathrm{t}$ - and $\mathrm{P}$ - values of biting force upon changing the vertical dimension of occlusion in the right side.

\begin{tabular}{|l|r|r|r|c|}
\hline & $\begin{array}{c}\text { Mean } \\
\text { values }\end{array}$ & St. D. & $\begin{array}{c}\text { Paired } \\
\text { "t” value }\end{array}$ & P-value \\
\hline $\begin{array}{l}\text { VDO versus } \\
\text { VDO +3mm }\end{array}$ & -0.9100 & \pm 0.893 & -3.220 & $0.010^{* *}$ \\
\hline $\begin{array}{l}\text { VDO versus } \\
\text { VDO +6mm }\end{array}$ & 1.0400 & \pm 0.970 & 3.0 .387 & $008^{* *}$ \\
\hline $\begin{array}{l}\text { VDO versus } \\
\text { VDO -3mm }\end{array}$ & 1.2000 & \pm 0.563 & 6.732 & $0.000^{* *}$ \\
\hline $\begin{array}{l}\text { VDO versus } \\
\text { VDO -6mm }\end{array}$ & 2.3300 & \pm 1.101 & 6.689 & $0.000^{* *}$ \\
\hline
\end{tabular}

VDO Vertical Dimension of Occlusion

** highly significant at $P<0.01$

TABLE (2) The mean differences, standard deviations, paired $\mathrm{t}$ - and $\mathrm{P}$ - values of biting force upon changing the vertical dimension of occlusion in the left side.

\begin{tabular}{|l|c|c|c|c|}
\hline & Mean & St. D & $\begin{array}{c}\text { Paired } \\
\text { "t" value }\end{array}$ & P-value \\
\hline $\begin{array}{l}\text { VDO versus } \\
\text { VDO +3mm }\end{array}$ & -0.7400 & \pm 0.76187 & -3.072 & $0.013^{* *}$ \\
\hline $\begin{array}{l}\text { VDO versus } \\
\text { VDO +6mm }\end{array}$ & 0.9600 & \pm 0.96056 & 3.160 & $0.012^{* *}$ \\
\hline $\begin{array}{l}\text { VDO versus } \\
\text { VDO -3mm }\end{array}$ & 1.3600 & \pm 0.86948 & 4.946 & $0.001^{* *}$ \\
\hline $\begin{array}{l}\text { VDO versus } \\
\text { VDO -6mm }\end{array}$ & 2.0200 & \pm 1.00753 & 6.340 & $0.000^{* *}$ \\
\hline
\end{tabular}

VDO Vertical Dimension of Occlusion

** highly significant at $P<0.01$ 


\section{DISCUSSION}

Vertical dimension is a highly debated topic in dentistry. Differences of opinion over how vertical dimension should be established, whether it can be modified, and what the outcome of modification will be can become confusing for those dentists searching for the right treatment for their patients. The fact is that there are multiple different approaches because there are several correct ways to alter vertical dimension ${ }^{(20)}$.

The effect of changes of the vertical dimension of occlusion on the biting forces or electromyographic activities of the masticatory muscles has been studied by many investigators ${ }^{(5,19)}$. The vertical dimension of occlusion is not the position at which the most efficient exertion of the biting forces is obtained, and that the bite force increased in proportion to increase the vertical dimension. ${ }^{(5,21,22)}$.

Alteration in the vertical dimension of occlusion can affect esthetics of soft facial tissues and can induce speech difficulties and muscle discomfort. (23) Results of experiments that increased vertical dimension both in subjects with natural teeth and with complete dentures have been interpreted as deranging the function of muscles and joints of the masticatory system, and therefore often held to be a hazardous procedure in prosthetic treatment. ${ }^{(9} .^{24)}$

In this study; the seat areas that accommodate the load cell for measuring the biting force were prepared at the premolar areas. The center and magnitude of a vertical component of occlusal forces in complete denture wearers were examined, and observed at the middle of the edentulous dental arch. ${ }^{(23)}$ Many investigators suggested that maximum biting force produced by a unilateral biting ${ }^{(17)}$, while other investigators suggested that the experimental measurements of vertical occlusal forces are not affected by whether the jaw is supported bilaterally or has all their forces on one side. ${ }^{(20)}$ Therefore in the present study the biting force was measured unilaterally. The results in this study indicate that the vertical dimension of occlusion is not an optimal vertical dimension which produces the greatest biting force, and that the biting force increased as the vertical dimension was increased. With further increase in the vertical dimension the biting force was decreased.

The results of the present study seems to be in agreement with those of Mackenna and Turker ${ }^{(25)}$ who constructed a gnathodynamometer to study the effect of varying degree of jaw opening on the maximum incising forces. They found that the incising force was greatest with $3 \mathrm{~mm}$ increasing in the vertical distance, and as the vertical distance was decreased or increased from this distance, the strength of the maximum incising force was decreased. The authors found that the biting forces were increased with an increase in the vertical dimension while the electromyographic activity was maintained at a constant value, and also that the electromyographic activity decreased with an increase in the vertical dimension when the bite force was maintained at a constant value ${ }^{(26)}$.

The results in this study are not in accord with that of Boos ${ }^{(19)}$ who applied an intra-oral pressure gauge (a gnathodynamometer) to measure the biting force. The author found that there was a point of maximum power around the rest position of the mandible, and that the optimum opening was $0 \mathrm{~mm}$. The author advised that the occlusal vertical dimension would be set slightly lower (about 1.5 $\mathrm{mm}$ ) than this point. The variations in the results of the present study and that of Boos may be due to that Boos used (Bimeter) to measure the biting force. The bimeter was positioned at the center of the mouth, which resulted in impingement of the tongue during function, and that the bimeter also might cause pain and apprehension.

\section{CONCLUSIONS}

The vertical dimension of occlusion is not an optimal vertical dimension that produces the maximum biting forces, and that the maximum biting forces obtained at a higher vertical dimension than the vertical dimension of occlusion. 


\section{REFERENCES}

1- Heartwell, C. M. and Rahn, A. O: Syllabus of complete denture. $4^{\text {th }}$ ed. Philadelphia: lea \& Febiger, 1986; PP : 228-230.

2- Bloom D Padayachy N. Increasing occlusal vertical dimension - Why, when and how. British Dental Journal 2006: 200, $251-256$.

3- Beyron, H. L. : Characteristics of functionally optimal occlusion and principles of occlusal rehabilitation. J. Am. Dent. Assoc. 1954; 48 : 648-656.

4- Storey, A. T : Physiology of a changing vertical dimension. J. Prosthet. Dent. 1962; 12: 912-916.

5- Manns, A.; Miralles, R. and Palazzi, C. : EMG, bite force, and elongation of the masseter muscle under isometric voluntary contractions and variations of vertical dimension. J. Prosthet. Dent. 1979; 42 : 674-682.

6- Academy of Prosthodontics: The glossary of Prosthodontic Terms. J. Prosthet. Dent. 2005; 94 : 11-92.

7- Garnick, J. and Ramfjord, S. P. : An elrctromyographic and clinical investigation. J. Prosthet. Dent. 1962; 12 :895-911.

8- Lindauer, S. J.; Gay, T. and Rendell, J. : Electromyographic-force characteristics in the assessment of oral function. J. Dent. Res. 1991; 70 : 1417-1422.

9- Christensen, J. : Effect of occlusion-raising procedures on the chewing system. Dent . Pract. 1970; $20: 233-238$.

10- Gunnar, E.; Carlsson. B. I. and Gulumser, K. : Effect of increasing vertical dimension on the masticatory system in subjects with natural teeth. J. Prosthet. Dent. 1979; 41 : 284-289.

11- Wessberg, G. A.; O`Ryan, F. S.; Washburn, M. C. and Epker, B. N. : Neuromuscular adaptation to surgical repositioning of the maxilla.J.Maxillofac. Surg. 1981;9:117-122 .

12- Lyons, F. M. : An electromyographic study of masticatory muscle activity at increased occlusal vertical dimension in complete denture wearers. J. Prosthet. Dent. 1988; 60: 346-348.

13- Mohindra, N.K and Bulman, J. S. : The effect of increasing vertical dimension of occlusion on facial aesthetics. Br. Dent. J. 2002; 192 : 164-168.
14- Rhan, A. O. and Heartwell, C. M. : Text book of complete denture fifth edition; Philadelphia: lea \&Febiger, 2002; pp: 243-248.

15- Rivera, C . W. and Norman, D . M. : Relationship of occlusal vertical dimension to the health of masticatory system. J. Prosthet. Dent. 1991; 65 : 547-553.

16- Tarbet,W.J.; Silverman, G and Schmidt, N.F.: Maximum incising biting force in denture wearers as influenced by adequacy of denture bearing tissues and the use of an adhesive. J. Dent. Res. 1981; 60 : 115-119.

17- Pruim, G .T : Asymmetries of bilateral static bite forces in different location on the human mandible. J. Dent. Res. 1979; 58 : 1685-1687.

18- Fontijn-Tekamp, F.A. ; Slagter, A.P. ; Van- Der B. A. ; Van THMA, Witter, D.J.; Kalk, W. and Jansen, J.A. : Biting and chewing in overdentures, full denture, and natural dentitions. J. Dent . Res.2000; $79: 1519-1524$.

19- Boos, R.H.: Intermaxillary relation established by biting power. J. Am. Dent. Assoc. 1940; 27 : 1129-1199.

20- Frank M. Spear Approaches to Vertical Dimension. Advanced Esthetics \& Interdisciplinary Dentistry2006:2; 2-12.

21- Kapur, K. K., and Soman, S.: The effect of denture factors on masticatory performance, Part III. The location of the food platforms. J. Prosthet. Dent. 1965;15 : 451-458.

22- Gross, M. and Ormianer, Z.: A preliminary study on the effect of occlusal vertical dimension increase on mandibular postural rest position. Int. J. Prosthod. 1988; 7 : 216-226.

23- Ogata, K. and Satoh, M.: Centre and magnitude of vertical forces in complete denture wearers. J. Oral Rehabil. 1995; 22 : 113-119.

24- Chafka, A.M. ; Mehta, N.R. ; Forgione, A.G. ; Al-Badawi, E.A.; Lobo, S.L. and Zawawi, K.H.: The effect of stepwise increases in vertical dimension of occlusion on isometric strength of cervical flexors and deltoid muscles in nonsymptomatic females. Cranio. 2002; 20 : 264-273.

25- Mackinna, B.R. and Turker, K.S.: Jaw separation and maximum incising force. J. Prosthet. Dent. 1983; 49 :726-731.

26- Morimoto, T.; Abekura, H. ; Tokuyama, H. and Hamada, T.: Alteration in the bite force and EMG activity with changes in the vertical dimension of edentulous subjects. J. Oral Rehabil. 1996; 32, 336-341. 